\title{
A simple method to evaluate the seismic/infrasonic energy partitioning during an eruption using data contaminated by air-to-ground signals
}

Mie Ichihara ( $\square$ ichihara@eri.u-tokyo.ac.jp)

The University of Tokyo https://orcid.org/0000-0002-5591-7129

Kazuya Yamakawa

The University of Tokyo: Tokyo Daigaku

Dan Muramatsu

Kyushu University: Kyushu Daigaku

\section{Research Article}

Keywords: Infrasound, Seismo-acoustic observation, Volcano, Ground-coupled air wave.

Posted Date: July 14th, 2021

DOI: https://doi.org/10.21203/rs.3.rs-707480/v1

License: (c) (i) This work is licensed under a Creative Commons Attribution 4.0 International License.

Read Full License 
1. A simple method to evaluate the seismic/infrasonic energy par2 titioning during an eruption using data contaminated by air-to3 ground signals

4 Mie Ichihara, Earthquake Research Institute, University of Tokyo, Tokyo 113-0032, Japan, ichihara@eri.u-tokyo.ac.jp Kazuya Yamakawa, Earthquake Research Institute, University of Tokyo, sanga@eri.utokyo.ac.jp

Dan Muramatsu, Kyushu University, muramatsu@sevo.kyushu-u.ac.jp 


\section{Abstract}

7 A volcanic eruption transmits both seismic waves and infrasound signals. The seismo-acoustic power 8 ratio is widely used to investigate the eruption behaviors and the source dynamics. It is often the case 9 that seismic data during an eruption are significantly contaminated or even dominated by ground 10 shaking due to infrasound (air-to-ground signals). To evaluate the contribution of infrasound-originated 11 power in the seismic data, we need a response function of the seismic station to infrasound. It is rare to obtain a seismo-acoustic data-set containing only infrasound signals, though it is ideal for calculating the response function. This study proposes a simple way to calculate the response function using seismo-acoustic data containing infrasound and independent seismic waves. The method requires data recorded at a single station and mainly uses the cross-correlation function between the infrasound data and the Hilbert transform of the seismic data. It is tested with data recorded by a station at Kirishima volcano, Japan, of which response function has been constrained. It is shown that the method calculates a proper response function even when the seismic data contain more significant seismic power (or noise) than the air-to-ground signals. The proposed method will be useful in monitoring and understanding eruption behaviors using seismo-acoustic observations.

\section{Keywords}

Infrasound, Seismo-acoustic observation, Volcano, Ground-coupled air wave.

\section{Introduction}

A propagating acoustic wave in the atmosphere induces local ground oscillation [Ben-Menahem and Singh, 1981, Sabatier et al., 1986]. Therefore, it is recorded not only by infrasound sensors but also by seismic sensors. Such signals in seismometer data are called 'ground-coupled air waves' in recent papers in volcanology [e.g., Johnson and Malone, 2007; De Angelis et al., 2012; Fee et al., 2016; Smith et al., 2016; McKee et al., 2018; Matoza et al., 2019]. However, the term 'ground-coupled airwaves' was originally used to indicate the pressure oscillation generated by propagating seismic waves [Donn and Posmentier, 1964]. The bidirectional usage of the term has confused the discussion. Matoza and Fee [2014] distinguished air-ground coupling and ground-air coupling. In this manuscript, we call the former 
in seismometer records as an air-to-ground signal and the latter in acoustic records as a ground-to-air signal to clarify the coupling direction.

The generation efficiency of the air-to-ground signal is $\sim 0.1-10 \mu \mathrm{m} / \mathrm{s} / \mathrm{Pa}$ [Ichihara 2016; Novoselov et al., 2020], which is much larger than that of the ground-to-air signal $(\sim 0.0003 \mathrm{~Pa} /(\mu \mathrm{m} / \mathrm{s}))[\mathrm{e} . \mathrm{g} ., \mathrm{Kim}$ et al., 2004; Watada et al., 2006; Ichihara et al., 2012; Kurokawa and Ichihara, 2020], the former is usually more significant in the seismo-acoustic observation during volcanic eruptions. The air-to-ground signals recorded by seismometers are used to investigate infrasound when few infrasound sensors are available [Johnson and Malone, 2007; Ichihara et al., 2012; De Angelis et al., 2012; McKee et al., 2018]. On the other hand, they can make a significant power in the seismometer records and disturb the analyses of seismic signals associated with eruptions [Nakamichi et al, 2013; Ichihara, 2016] and other surface phenomena like snow avalanches [Heck et al., 2019; Marchetti et al., 2020].

The Volcanic Acoustic-Seismic Ratio (VASR) that is the infrasonic power over the seismic power [Johnson and Aster, 2005], has been used to investigate the energy partitioning between seismic waves and infrasonic waves. The energy partitioning allows us to infer the change of eruptive behaviors [Sciotto et al., 2011; Johnson and Aster, 2005; Ichihara, 2016, Palacios et al., 2016]. When the same eruption mechanism is kept, the seismic and infrasonic eruption tremors tend to vary their amplitudes with the eruption parameter, like plume height, keeping their ratio constant [Ichihara, 2016; Fee et al., 2016; Haney et al., 2018; Sciotto et al., 2019]. In such situations, it is particularly important to distinguish whether the power ratio of seismic and infrasonic data represents the seismic-infrasonic energy partitioning or the ground response to the incident infrasound [Ichihara, 2016]. More essentially, we need to distinguish if the recorded signal is seismic or infrasonic waves. It is achieved by the propagation velocity when seismic arrays are available [Nakamichi et al., 2013, Heck et al., 2019; Marchetti et al., 2020].

Kurokawa and Ichihara [2020] used known seismic waves and acoustic waves recorded by an infrasound sensor and a collocated seismometer as references. They calculated the spectral power ratios between them to evaluate the ground-to-air coupling and air-to-ground coupling efficiency. They used airplane sound as the known acoustic signal, though it has frequency components and incident angles much higher than those of volcanic signals. On the other hand, Ichihara [2016] obtained the ground response to infrasound as a function of frequency at a station in Kirishima volcano, Japan (Fig. 1). This case is unique in that a good infrasound source is available: Sakurajima, about $42 \mathrm{~km}$ away (Fig. 1c), frequently transmits explosion infrasound (Fig. 1a). Because of the distance, seismic waves from the source do not 
reach the stations at Kirishima, or if they do, they are well separated in time from the infrasound signals. The response function, consisting of the amplitude ratio (Fig. 1d) and the phase shift of the vertical ground velocity to the pressure data (Fig. 1e), was obtained using the beginning $10 \mathrm{~s}$ containing the strong pulse (including $3 \mathrm{~s}$ before the onset), and those from 15 events were stacked [Ichihara, 2016].

In general, such an ideal infrasound source is rare in the field. Although the previous study assumed the reference data, both seismic and infrasonic, include only infrasound signals, the seismic data may always contain seismic waves when volcanoes are active. This paper presents a convenient method to evaluate the response function and examine the contribution of the air-to-ground signals in seismometer records using data containing both seismic and infrasonic signals. The method requires only an infrasound sensor and a collocated seismometer without significant wind noise. If there is an additional infrasound station, we can also correct for the wind noise effect.

\section{Basic Theory}

We denote vertical ground velocity recorded by a seismometer as $d_{v}$ and pressure change recorded by an infrasound sensor as $d_{p}$. For simplicity, we assume the incident waves are dominated by a single seismic wave $\left(v_{s}\right)$ and a single infrasonic wave $\left(p_{a}\right)$. We assume that $d_{v}$ consists of $v_{s}$, an air-to-ground signal $\left(v_{a}\right)$ generated by $p_{a}$, and wind-induced ground oscillation $\left(v_{w}\right)$, while $d_{p}$ consists of $p_{a}$ and wind noise $\left(p_{w}\right)$. The contribution of the ground-to-air signals is assumed negligible, as mentioned above.

These assumptions are represented by

$$
d_{v}=v_{s}+v_{a}+v_{w}, \quad d_{p}=p_{a}+p_{w}
$$

A cross-correlation function between two time series, $d_{1}$ and $d_{2}$, in a given time window $[t, t+T]$ is represented by

$$
C C\left(d_{1}, d_{2} ; t ; \tau\right) \equiv \frac{1}{T} \int_{t}^{t+T} d_{1}\left(t^{\prime}\right) d_{2}\left(t^{\prime}-\tau\right) d t^{\prime}
$$

where $\tau$ is the time delay of $d_{1}$ to $d_{2}$. The corresponding cross correlation coefficient $R\left(d_{1}, d_{2} ; t ; \tau\right)$ is

$$
R\left(d_{1}, d_{2} ; t ; \tau\right) \equiv \frac{C C\left(d_{1}, d_{2} ; t ; \tau\right)}{\sqrt{E\left(d_{1} ; t\right)} \sqrt{E\left(d_{2} ; t\right)}},
$$

83 where $E(d ; t)$ represents the power of a time series $d$ in the time window $[t, t+T]$, namely,

$$
E(d ; t) \equiv C C(d, d ; t ; 0)
$$

Hereafter, we omit $t$ that specifies the time window. 
Among $v_{s}, v_{a}, v_{w}, p_{a}$, and $p_{w}$ in equation (1), we assume no pair except $v_{a}$ and $p_{a}$ has a correlation. Although $v_{s}$ and $p_{a}$ may have a correlation if their source is common, their correlation should be found with a time shift much larger than that of $v_{a}$ to $p_{a}$, considering the velocity difference between the seismic waves and infrasound [Ichihara et al., 2012]. The correlation between $v_{w}$ and $p_{w}$ is small if the distance between the infrasound sensor and the seismometer is larger than the correlation length of wind noise. For example, the distance of $5 \mathrm{~m}$ is enough to suppress the wind-noise correlation at frequency $>1 \mathrm{~Hz}$ in ordinary wind conditions [Shields, 2005, Ichihara et al., 2012]. Therefore,

$$
\begin{aligned}
R\left(d_{v}, d_{p} ; \tau\right) & =\frac{C C\left(v_{a}, p_{a} ; \tau\right)}{\sqrt{E\left(d_{v}\right)} \sqrt{E\left(d_{p}\right)}}, \\
E\left(d_{v}\right) & =E\left(v_{s}\right)+E\left(v_{a}\right)+E\left(v_{w}\right), \\
E\left(d_{p}\right) & =E\left(p_{a}\right)+E\left(p_{w}\right)=\left(1+W_{p}\right) E\left(p_{a}\right),
\end{aligned}
$$

where $W_{p}$ represent the power ratio of the wind noise to the waves. Under the same wind condition, the infrasound data are usually more significantly affected by wind noise. Therefore, we neglect $E\left(v_{w}\right)$ compared with $E\left(v_{s}\right)+E\left(v_{a}\right)$ in the following discussion.

It is noted that $R\left(d_{v}, d_{p} ; \tau\right), E\left(d_{v}\right)$, and $E\left(d_{p}\right)$ are calculated from the observed data. Our aim here is to estimate $E\left(v_{a}\right) / E\left(p_{a}\right)$ to obtain the seismo-acoustic power ratio $E\left(v_{s}\right) / E\left(p_{a}\right)$ from the observed data.

It is assumed that $p_{a}$ is propagating along the ground surface in the direction of the $x$-axis. The component of angular frequency $(\omega)$ of $p_{a}$ is

$$
p_{a \omega}=P_{\omega} \exp \left[i \omega\left(t-\frac{x}{\alpha}\right)\right],
$$

where $\alpha$ is the sound speed in the atmosphere, and $\omega$ is the angular frequency. When the ground is a homogeneous elastic half space, and its seismic speeds are much larger than $\alpha$, the vertical ground velocity $\left(v_{a \omega}\right)$ induced by $p_{a \omega}$, is

$$
v_{a \omega}=H_{p s} e^{-\frac{i \pi}{2}} P_{\omega} \exp \left[i \omega\left(t-\frac{x}{\alpha}\right)\right], \quad H_{p s} \equiv \frac{\alpha}{2(\lambda+\mu)}\left(\frac{\lambda+2 \mu}{\mu}\right),
$$

where $(\lambda, \mu)$ are the Lamé's constants of the ground [Ben-Menahem and Singh, 1981].

Equation (9) indicates that $v_{a \omega}$ has a phase shift of $-\pi / 2$ with respect to $p_{a \omega}$, and this phase shift does not depend on the frequency. The actual ground is not homogeneous or flat, and the incident infrasound wave is not necessarily along the ground surface. Nevertheless, the phase shift of $-\pi / 2$ is observed in many places [Ichihara et al., 2012; Ichihara, 2016]. Although the sensor distance can cause a time shift of correlation, we can correct it [McKee et al., 2018]. On the other hand, the phase delay 
significantly deviates from the theoretical value and fluctuates at high frequency (Fig. 1e), possibly due to the ground structure [Ichihara, 2016]. Besides, $H_{p s}$ depends on the frequency, especially in the low frequency (Fig. 1d). Therefore, it is difficult to estimate the response function theoretically. Here we derive an equation relating $H_{p s}$ and the observed data, assuming the phase shift is $-\pi / 2$. The relation is tested with data in the following sections.

First, the phase of $d_{v}$ is shifted by $\pi / 2$, using the Hilbert transform, $h_{i}\left(d_{v}\right)$, as

$$
d_{v}^{h}=-\operatorname{Imag}\left[h_{i}\left(d_{v}\right)\right]
$$

where Imag $[\cdot]$ takes the imaginary part. The phase-shifted time series are denoted with a subscript $h$, namely,

$$
d_{v}^{h}=v_{s}^{h}+v_{a}^{h}+v_{w}^{h} .
$$

Second, we calculate $R\left(d_{v}^{h}, d_{p} ; \tau\right)$, and search its maximum around $\tau=0$. We denote $\tau$ that gives the maximum as $\tau_{\max }$. It should be consistent with the propagation time of infrasound between the infrasound sensor and the seismometer. When any signals in $d_{v}$, other than $v_{a}$, correlate with $p_{a}, C C\left(d_{v}^{h}, d_{p} ; \tau\right)$ tends to have a maximum significantly deviated from the expected time delay [Ichihara et al., 2012]. Such data sets are not adequate to use in the current method.

Third, we approximate

$$
C C\left(d_{v}^{h}, d_{p} ; \tau_{\max }\right)=C C\left(v_{a}^{h}, p_{a} ; \tau_{\max }\right)=H_{p s} E\left(p_{a}\right) \sim H_{p s} E\left(d_{p}\right) .
$$

The last approximation holds with negligible wind noise. We use equations (12) and (5) to obtain

$$
H_{p s} \sim \frac{C C\left(d_{v}^{h}, d_{p} ; \tau_{\max }\right)}{E\left(d_{p}\right)}=R\left(d_{v}^{h}, d_{p} ; \tau_{\max }\right) \sqrt{\frac{E\left(d_{v}^{h}\right)}{E\left(d_{p}\right)}} .
$$

\section{This equation estimates $H_{p s}$ using only the observed data.}

When the wind noise is significant, we need another infrasound station close by to evaluate the relation between $E\left(d_{v}\right)$ and $E\left(p_{a}\right)$. The calculation with wind noise is given in Additional File 1. Because $H_{p s}$ is the site property of the station, it should not change significantly with time. Therefore, we evaluate it using equation (13) as an average of the adequately selected time windows.

Considering $E\left(v_{a}\right)=H_{p s}^{2} E\left(p_{a}\right)$ and $E\left(d_{p}\right) \sim E\left(p_{a}\right)$, we obtain

$$
\frac{E\left(d_{v}\right)}{E\left(d_{p}\right)} \sim \frac{E\left(v_{s}\right)}{E\left(p_{a}\right)}+H_{p s}^{2} .
$$

It is noted that this equation is applicable on the condition that an infrasound singal $p_{a}$ exists. Equation (14) indicates that we should refer to $H_{p s}^{2}$ for interpreting the observed power ratio, $E\left(d_{v}\right) / E\left(d_{p}\right)$. The 
seismic power $E\left(v_{s}\right)$ increases the power ratio above $H_{p s}^{2}$. Equation (14) is particularly useful when the air-to-ground signal is comparable with the seismic power. We can also identify the condition of $E\left(v_{s}\right) \ll H_{p s}^{2}$, in which the observed $E\left(d_{v}\right) / E\left(d_{p}\right)$ cannot provide the meaningful seismic-acoustic energy partitioning.

With wind noise, equation (14) becomes

$$
\frac{E\left(d_{v}\right)}{E\left(d_{p}\right)}=\frac{1}{1+W_{p}}\left[\frac{E\left(v_{s}\right)}{E\left(p_{a}\right)}+H_{p s}^{2}\right]
$$

(Additional File 1). When $E\left(d_{v}\right) / E\left(d_{p}\right)<H_{p s}^{2}$, it indicates that $E\left(d_{p}\right)$ is significantly contaminated by the wind noise power, and thus $E\left(d_{v}\right) / E\left(d_{p}\right)$ is not useful, either.

\section{Method to estimate $H_{p s}$ from data}

We use the data presented in Fig. 1a and $1 \mathrm{~b}$ as $d_{p}$ and $d_{v}$, respectively. They are infrasound from Sakurajima recorded by an infrasound sensor (Hakusan, SI102, 0.1-1000 Hz) and a seismometer (Nanometrics, Trillium 120P) at Kirishima, respectively. The sampling rate is $100 \mathrm{~Hz}$ for both data. Ichihara [2016] has shown that the part of $d_{v}$ containing the air-to-ground signal is well reproduced by $d_{p}$ with the response function at 1-7 Hz shown by the red dashed line in Fig. 1d and 1e.

As the infrasound signal is larger than the background wind noise (Fig. 1a), we assume $W_{p}=0$ in the following analysis. On the other hand, there is noticeable oscillation before the arrival of infrasound in the seismograph (Fig. 1b), indicating that the background seismic signal is comparable with the airto-ground signal. Specifying the origin of the background signal is out of the scope of this study. Here we treat all signals other than $v_{a}$ in $d_{v}$ as $v_{s}$.

We use the four frequency bands: $1-3.5 \mathrm{~Hz}, 3.5-7 \mathrm{~Hz}, 7-12 \mathrm{~Hz}$, and $12-18 \mathrm{~Hz}$. For the selection of the frequency bands, we refer to the feature of the known response function shown in Fig. 1d and 1e. The phase shift of $d_{v}$ to $d_{p}$ is constant around $-\pi / 2$ at $1-7 \mathrm{~Hz}$, while the amplitude ratio $H_{p s}$ is relatively stable in 7-18 Hz. In general cases without known response functions, we may arbitrarily select the frequency bands.

We apply a zero-phase-shift band-pass filter to $d_{p}$ and $d_{v}$ and calculate the cross-correlation coefficient, $R\left(d_{v}, d_{p} ; \tau\right)$, in the individual bands. Figure 2 shows the results, in which the time origin is taken at the onset of the infrasound signal. In each of Fig. 2a-2d, the lowest panel shows $R\left(d_{v}, d_{p} ; \tau\right)$, calculated in a 2.56 -second-long time window sliding every $0.5 \mathrm{~s}$. We can clearly see the typical correlation pattern of 
air-to-ground signals, that is a positive peak in $\tau>0$ and a negative peak in $\tau<0$ with a node at $\tau=0$ [Ichihara et al., 2012], continuously after the arrival of the infrasound. It confirms that $d_{p}$ includes $p_{a}$ in the period in all the frequency bands.

We use the band-pass-filtered data in $120 \mathrm{~s}$ after time zero as $d_{p}$ and $d_{v}$. First, we shifted the phase of $d_{v}$ forward by $\pi / 2$ to obtain $d_{v}^{h}$. Second, we calculate $R\left(d_{v}^{h}, d_{p} ; \tau\right)$. Third, we take the maximum of $R\left(d_{v}^{h}, d_{p} ; \tau\right)$, denoted as $R_{\text {max }}$, in $\tau= \pm 0.01$. This span, corresponding to one data point, is allowed, considering the time delay between the two sensors separated by $\sim 5 \mathrm{~m}$ and possible phase delay due to noise. Fourth, we calculate $E\left(d_{p}\right)$ and $E\left(d_{v}^{h}\right)$ by the mean square of the data. Finally, we calculate $H_{p s}$, using equation (13).

\section{Result and discussion}

Figure 3a compares the value of $H_{p s}$ obtained by the current method and by Ichihara [2016]. They are consistent. It is noted that the previous value was obtained using the beginning $10 \mathrm{~s}$ of 15 events, while the current value was obtained from the 120-second-long data of a single event. Figure $3 \mathrm{~b}$ shows the corresponding $R\left(d_{v}^{h}, d_{p} ; \tau\right)$ for each band. They have the maximum values within $\tau \pm 0.01 \mathrm{~s}$, confirming that the phase shift of $-\pi / 2$ was successfully corrected.

The data used in this analysis are ideal to evaluate $H_{p s}$ because $d_{p}$ and $d_{v}$ mainly include $p_{a}$ and $v_{a}$, respectively. We do not always have such data sets. We evaluate the effect of $v_{s}$ with the assumption that $v_{s}$ is independent of $p_{a}$. We artificially add $v_{s}$ made in the following way. We generate a random function that is centered at zero and has the same length as $d_{v}$. We apply the same band-pass filter to this function and call it as $d_{b g}$. We normalize $d_{b g}$ to have the same energy as $d_{v}$, by multiplying it by $\sqrt{E\left(d_{v}\right) / E\left(d_{b g}\right)}$. Then, we amplify it by an arbitrary factor $\Gamma$ to make a hypothetical $v_{s}$. Namely,

$$
v_{s}=\Gamma d_{b g} \sqrt{\frac{E\left(d_{v}\right)}{E\left(d_{b g}\right)}}
$$

Assuming the original $d_{v}$ purely consists of $v_{a}$, that is $E\left(d_{v}\right)=E\left(v_{a}\right), \Gamma$ is regarded as $\sqrt{E\left(v_{s}\right) / E\left(v_{a}\right)}$. The actual $\sqrt{E\left(v_{s}\right) / E\left(v_{a}\right)}$ should be larger than $\Gamma$ because $d_{v}$ contains some background signal other than $v_{a}$. We may see it by comparing the amplitudes before and after the infrasound arrival in $d_{v}$ and $d_{p}$ (Fig. 2). It is also supported by Fig. 3b that $R_{\max }<1$.

Including $v_{s}$ into $d_{v}$, we follow the same procedure as the previous paragraph to calculate $H_{p s}$. For each frequency and each $\Gamma$, we tested with 100 random functions. The mean and the standard deviation 
of $H_{p s}, \tau_{\max }$, and $R_{\max }$ are presented as functions of $\sqrt{E\left(v_{s}\right) / E\left(v_{a}\right)}$ in Fig. 4a, 4c, and 4d, respectively. We also show the relation of the individual $H_{p s}$ and $R_{\max }$ in Fig. 4b. As the background signal power, $E\left(v_{s}\right)$, increases, the cross-correlation coefficient decreases (Fig. $4 \mathrm{~d}$ ). On the other hand, $H_{p s}$ stays around the expected value (Fig. $4 \mathrm{a}$ and $4 \mathrm{~b}$ ). The average values are almost the same as those without artificial noise, $H_{p s}^{0}$ (the closed circles on the vertical axis in Fig. 4a).

The same test is performed using actual seismic data recording volcanic tremors. Shinmoe-dake, an active cone of Kirishima volcano, had sub-plinian eruptions in 2011 [Nakada et al., 2013], three weeks after the signal in Fig. 1 was recorded. A volcanic tremor continued there from 18 January 2011 to the first sub-plinian eruption on 26 January 2011. Two phreatic eruptions occurred at 1:27 a.m. (JST) on 19 January and 7:31 a.m. (JST) on 26 January 2011. The tremor always had power in the frequency range of 3.5-7 Hz [Ichihara and Matsumoto, 2017]. We randomly selected 100 windows with a length of $120 \mathrm{~s}$ between the two phreatic eruptions, apply the band-pass filter at 3.5-7 Hz, and use it for $d_{b g}$ in equation (16). Figure 5a, 5c, and 5d showed the result in the format to be compared with the green lines in Fig. $4 \mathrm{a}, 4 \mathrm{c}$, and $4 \mathrm{~d}$. The normalized spectra of the 100 signals $\left(d_{b g}\right)$ are shown in Fig. 5b. It is aligned in the increasing order of $\left(H_{p s}-H_{p s}^{0}\right) / H_{p s}^{0}$ for $\Gamma=10$, which is shown in the upper panel of (b). We could not identify the spectral features that deviate $H_{p s}$ from $H_{p s}^{0}$.

These results support that we can evaluate $H_{p s}$ properly, even if the seismic data are significantly contaminated by the background signal (seismic waves or other noise). When we have persistent infrasound and can average a long time window or many windows, we may estimate $H_{p s}$ more accurately.

\section{Conclusions}

We developed equation (13) that relates the ground response to infrasound $\left(H_{p s}\right)$ and the observed seismo-acoustic data $\left(d_{v}\right.$ and $\left.d_{p}\right)$. We have confirmed that it provides a proper value of $H_{p s}$, even when the observed seismic data contain significant seismic signals as well as the air-to-ground signals. Constraining $H_{p s}$ is essential for interpreting the observed seismic-acoustic power ratio to the energy partitioning between seismic waves and infrasound at the source.

\section{Availability of data and materials}

1 The datasets used and/or analysed during the current study are available from the corresponding author on reasonable request. 


\section{Competing interests}

The authors declare that they have no competing interests.

\section{Funding}

This study is funded by the Joint Usage Program of the Earthquake Research Institute, University of Tokyo (2019B01) and the Ministry of Education, Culture, Sports, Science and Technology (MEXT) of Japan, under its Earthquake and Volcano Hazards Observation and Research Program.

\section{Authors' contributions}

MI developed the methods, made the analyses, and drafted the manuscript. KY confirmed the equations. DM raised the needs in volcanology to motivate this study. All authors read and approved the final manuscript.

\section{Acknowledgments}

The data used in this study were corrected by the Volcano Research Center of Earthquake Research Institute, University of Tokyo.

\section{References}

Ben-Menahem A, Singh SJ (1981) Seismic Waves and Sources, 2nd ed.,.Dover, New York

De Angelis, S, Fee, D, Haney, M, Schneider, D (2012) Detecting hidden volcanic explosions from Mt. Cleveland Volcano, Alaska with infrasound and ground-coupled airwaves. Geophys Res Lett 39:L21312. doi:10.1029/2012GL053635

Donn, WL, Posmentier, ES (1964) Ground-coupled air waves from great Alaskan earthquake. J Geophys Res 69:5357-5361. doi:10.1029/JZ069i024p05357

Fee, D, Haney, M, Matoza, R, Szuberla, C, Lyons, J, Waythomas, C (2016) Seismic envelope-based detection and location of ground-coupled airwaves from volcanoes in Alaska. Bull Seis Soc Am, 106:1024-1035. doi:10.1785/0120150244

Fee, D, Lyons, J, Haney, M, Wech, A, Waythomas, C, Diefenbach, AK, Lopez, T, Van Eaton, A, Schneider, D (2020) Seismo-acoustic evidence for vent drying during shallow submarine eruptions at Bogoslof volcano. Bull Volcanol doi:10.1007/s00445-019-1326-5 
Haney, MM, Matoza, RS, Fee, D, Aldridge, DF (2018) Seismic equivalents of volcanic jet scaling laws and multipoles in acoustics. Geophys J Int 213:623-636. doi:10.1093/gji/ggx554 (2018)

Heck, M, Hobiger, M, van Herwijnen, A, Schweizer, J, Fah, D (2018) Localization of Seismic events produced by avalanches using multiple signal classification, Geophys J Int 216:201-217. doi:10.1093/gji/ggy394

Ichihara M, Takeo M, Yokoo A, Oikawa J, Ohminato T (2012) Monitoring volcanic activity using correlation patterns between infrasound and ground motion. Geophys Res Lett 39: L04304. doi:10.1029/2011GL050542

Ichihara M (2016) Seismic and infrasonic eruption tremors and their relation to magma discharge rate: A case study for sub-Plinian events in the 2011 eruption of Shinmoe-dake, Japan. J Geophys Res Solid Earth 121:7101-7118. doi:10.1002/2016JB013246

Ichihara M, Matsumoto S (2017) Relative source locations of continuous tremor before and after the subplinian events at Shinmoe-dake, in 2011. Geophys Res Lett. doi: 10.1002/2017GL075293

Johnson, JB. Aster, RC (2005) Relative partitioning of acoustic and seismic energy during Strombolian eruptions. J Volcanol Geotherm Res 148:334-354. doi:10.1016/j.jvolgeores.2005.05.002

Johnson, JB. Malone, SD (2007) Ground-coupled acoustic airwaves from Mount St. Helens provide constraints on the May 18, 1980 eruption. Earth Planet Sci Lett 258:16-31. doi:10.1016/j.epsl.2007.03.001

Kim TS, Hayward C, Stump B (2004) Local infrasound signals from the Tokachi-Oki earthquake. Geophys Res Lett 31: L20605. doi:10.1029/2004GL021178

Kurokawa, A.K., Ichihara, M (2020) Identification of infrasonic and seismic components of tremors in single-station records: application to the 2013 and 2018 events at Ioto Island, Japan. Earth Planets Space 72:171. doi:10.1186/s40623-020-01302-2

Matoza RS, Fee D (2014) Infrasonic component of volcano-seismic eruption tremor. Geophys Res Lett 41: 1964-1970. doi:10.1002/2014GL059301

Matoza, RS, Arciniega-Ceballos, A, Sanderson, RW, Mendo-Perez, G, Rosado-Fuentes, A, Chouet, BA (2019) High-broadband seismoacoustic signature of Vulcanian explosions at Popocatepetl Volcano, Mexico. Geophys Res Lett 466: 148-157. doi:10.1029/2018GL080802

Marchetti, E, van Herwijnen, A, Christen, M, Silengo, MC, Barfucci, G (2020) Seismo-acoustic energy partitioning of a powder snow avalanche. Earth Surf Dynam 8: 399-411. doi:10.5194/esurf-8-399-2020 
McKee K, Fee D, Haney M, Matoza RS, Lyons J (2018) Infrasound signal detection and back azimuth estimation using ground-coupled airwaves on a seismo-acoustic sensor pair. J Geophys Res Solid Earth 123: 6826-6844. doi:10.1029/2017JB015132

Nakada, S, Nagai, M, Kaneko, T, Suzuki, Y, Maeno, F (2013) The outline of the 2011 eruption at Shinmoe-dake (Kirishima), Japan. Earth Planets Space. doi:10.5047/eps.2013.03.016

Nakamichi, H., Yamanaka, Y, Terakawa, T, Horikawa, S, Okuda, T, Yamazaki, F (2013) Continuous long-term array analysis of seismic records observed during the 2011 Shinmoedake eruption activity of Kirishima volcano, southwest Japan. Earth Planets Space 65:551-562. doi:10.5047/eps.2013.03.002 Novoselov, A, Fuchs, F, Bokelmann, G (2020) Acoustic-to-seismic ground coupling: coupling efficiency and inferring near-surface properties. Geophys J Int 223:144-160. doi:10.1093/gji/ggaa304

Palacios, PB, Díez, M, Kendall, J-M, Mader, HM (2016) Seismic-acoustic energy partitioning during a paroxysmal eruptive phase of Tungurahua volcano, Ecuador. Geophys J Int 205:1900-1915. doi:10.1093/gji/ggw136

Sabatier, J, Bass, HE, Bolen, LN, Attenborough, K (1986) Acoustically induced seismic waves. J Acoust Soc Am 80:646-649. doi:10.1121/1.394058

Sciotto, M, Cannata, A, Di Grazia, G, Gresta, S, Privitera, E, Spina, L (2011) Seismoacoustic investigations of paroxysmal activity at Mt. Etna volcano: New insights into the 16 November 2006 eruption. J Geophys Res 116: B09301. doi:10.1029/2010JB008138

Sciotto, M, Cannata, A, Prestifilippo, M, Scollo, S, Fee, D, Privitera, E (2019) Unravelling the links between seismo-acoustic signals and eruptive parameters: Etna lava fountain case study. Sci Rep 9: 16417. doi: 10.1038/s41598-019-52576-w

Shields FD (2005) Low-frequency wind noise correlation in microphone arrays. J Acoust Soc Am doi:10.1121/1.1879252

Smith, CM, McNutt, SR, Thompson, G (2016) Ground-coupled airwaves at Pavlof Volcano, Alaska, and their potential for eruption monitoring. Bull Volcanol. doi:10.1007/s00445-016-1045-0

Watada S, Kunugi T, Hirata K, Sugioka H, Nishida K, Sekiguchi S, Oikawa J, Tsuji Y, Kanamori H (2006) Atmospheric pressure change associated with the 2003 Tokachi-Oki earthquake. Geophys Res Lett 33:L24306. doi:10.1029/2006GL027967 


\section{Figure Captions}

\section{Figure 1}

Infrasound from an explosion, at 22:38 (hh:mm JST) on 13 January 2011, of Sakurajima volcano recorded by an infrasound sensor (a) and a broad-band seismometer (b) at the SMN station near Kirishima volcano, $42 \mathrm{~km}$ to the north of Sakurajima. (c) The locations of Sakurajima and Kirishima, southern Kyushu, Japan. The amplitude (d) and phase (e) response of the ground velocity to incident infrasound at the SMN station. The red dots represent the response function at 1-7 Hz used by Ichihara [2016]. All the plots are reproduced from Ichihara [2016], but the phase delay in (e) has been converted from the range of $[-\pi, \pi]$ to $[-2 \pi, 0]$.

\section{Figure 2}

The cross-correlation analyses of the data in Fig. 1 at (a) 1-3.5 Hz, (b) 3.5-7 Hz, (c) 7-12 Hz, and (d) 12-18 Hz. In each panel, the top and middle panels show the band-passed infrasonic data $\left(d_{p}\right)$ and seismic data $\left(d_{v}\right)$, respectively. The bottom panel shows the cross-correlation coefficient between the seismic data, $d_{v}$, and infrasonic data, $d_{p}$, with the vertical axis representing the time delay, $\tau$, of $d_{v}$ to $d_{p}$. The horizontal dashed line indicates $\tau=0$.

\section{Figure 3}

(a) The amplitude response of the ground velocity to infrasound, $H_{p s}$, obtained by this study is shown for 1-3.5 Hz (red line), 3.5-7 Hz (green line), 7-12 Hz (blue dots), and 12-18 Hz (purple dots). The results are compared with the response function obtained by Ichihara [2016] (Fig. 1d and 1e). (b) The corresponding cross-correlation coefficient between the phase-shifted seismic data, $d_{v}^{h}$, and the infrasonic data, $d_{p}$. The colors indicate the frequency bands as in (a).

\section{Figure 4}

The effect of background seismic signals, $v_{s}$, in the seismic data, $d_{v}$, on the estimation of $H_{p s}$. The colors indicate the frequency bands: $1-3.5 \mathrm{~Hz}$ (red), 3.5-7 Hz (green), 7-12 Hz (blue), and 12-18 Hz (purple). A hundred random functions are band-pass filtered and used as $v_{s}$. The horizontal axis is the square-root of power ratio of $v_{s}$ to the original $d_{v}$ that is approximated as $v_{a}$. It is noted that the actual power ratio $E\left(v_{s}\right) / E\left(v_{a}\right)$ is larger than $E\left(v_{s}\right) / E\left(d_{v}\right)$ as $d_{v}$ itself contains a significant power of background signals. The lines and error bars show the means and the standard deviations of $H_{p s}$ (a), the maximum correlation coefficient, $R_{\max }(\mathrm{d})$, and the time delay, $\tau_{\max }$, that gives $R_{\max }(\mathrm{d})$ for the hundred random functions. The closed circles on the vertical axies are the values without $v_{s}$. The 
${ }_{327}$ relation between the individual $R_{\max }$ and $H_{p s}$ for all the cases are shown with circles in (b).

\section{$328 \quad$ Figure 5}

${ }_{329}$ A similar background-signal test as in Fig. 4, but volcanic tremors recorded by the same seismic station ${ }_{330}$ are used as $v_{s}$. We performed the analysis only at 3.5-7 Hz. We randomly selected 100-time windows 331 between 1:27 on 19 January 2011 and 7:31 on 26 January 2011, of which the normalized power-spectral 332 densities of the band-pass-filtered data are displayed in the lower panel of (b). The horizontal axis shows the window number of $v_{s}$ aligned in the increasing order the deviation of $H_{p s}$ for the case

${ }_{334} \sqrt{E\left(v_{s}\right) / E\left(v_{a}\right)}=10$. The upper frame shows the deviation: $\Delta H_{p s} \equiv\left(H_{p s}-H_{p s}^{0}\right) / H_{p s}^{0}$, where $H_{p s}^{0}$ is the 335 value obtained without $v_{s}$, which is the closed circle on the vertical axis in (a). In (a), (c), and (d), the ${ }_{336}$ lines and error bars show the means and the standard deviations of $H_{p s}, \tau_{\max }$, and $R_{\max }$, respectively. 


\section{Figures}
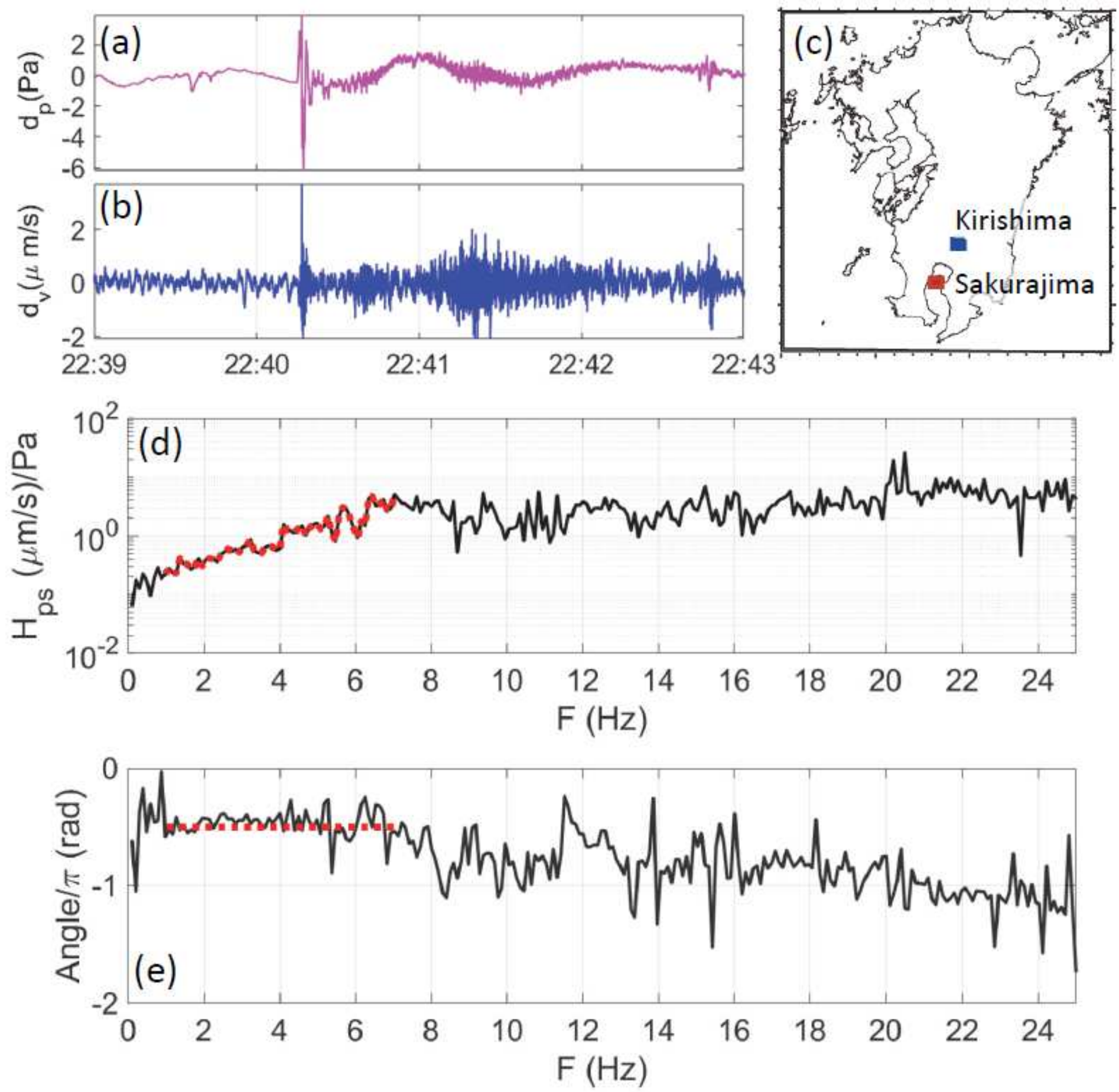

Figure 1

Infrasound from an explosion, at 22:38 (hh:mm JST) on 13 January 2011, of Sakurajima volcano recorded by an infrasound sensor (a) and a broad-band seismometer (b) at the SMN station near Kirishima volcano, $42 \mathrm{~km}$ to the north of Sakurajima. (c) The locations of Sakurajima and Kirishima, southern Kyushu, Japan. The amplitude (d) and phase (e) response of the ground velocity to incident 
infrasound at the SMN station. The red dots represent the response function at 1-7 $\mathrm{Hz}$ used by lchihara [2016]. All the plots are reproduced from Ichihara [2016], but the phase delay in (e) has been converted from the range of $[-\pi, \pi]$ to $[-2 \pi, 0]$.

(a)
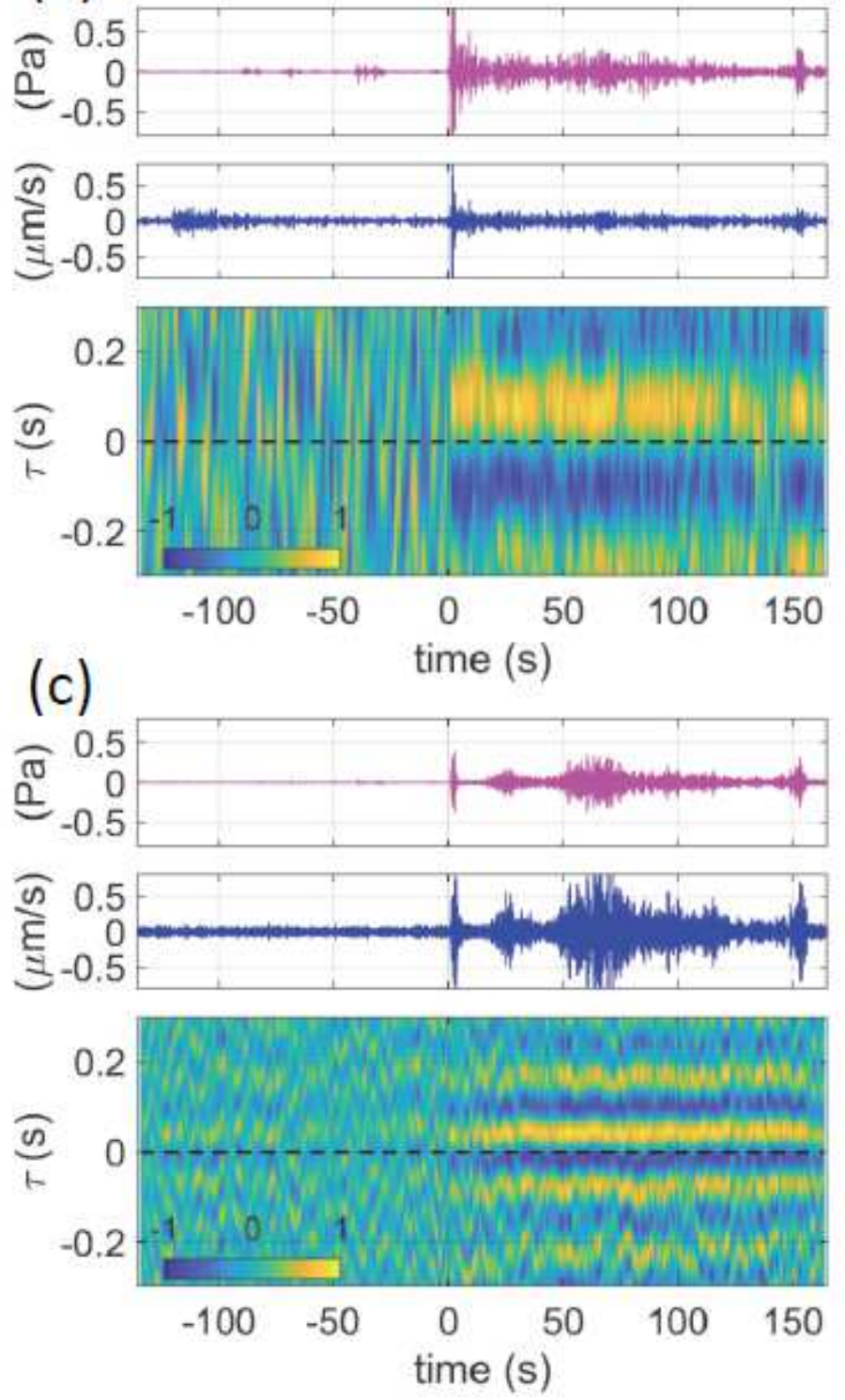

(b)
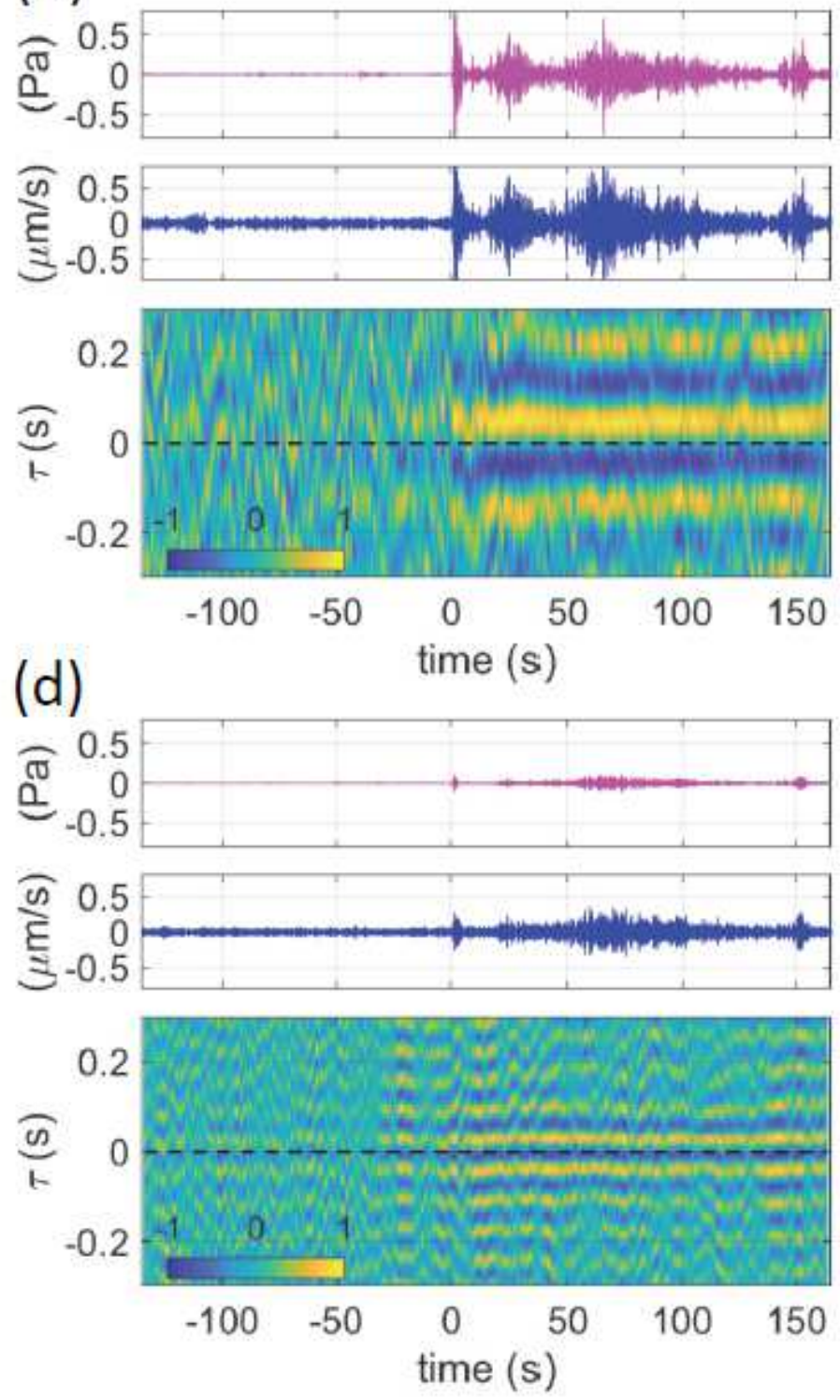

\section{Figure 2}

The cross-correlation analyses of the data in Fig. 1 at (a) $1-3.5 \mathrm{~Hz}$, (b) $3.5-7 \mathrm{~Hz}$, (c) $7-12 \mathrm{~Hz}$, and (d) $12-18$ $\mathrm{Hz}$. In each panel, the top and middle panels show the band-passed infrasonic data (dp) and seismic data (dv), respectively. The bottom panel shows the cross-correlation coefficient between the seismic data, $d v$, and infrasonic data, $d p$, with the vertical axis representing the time delay, $\tau$, of $d v$ to $d p$. The horizontal dashed line indicates $\tau=0$. 

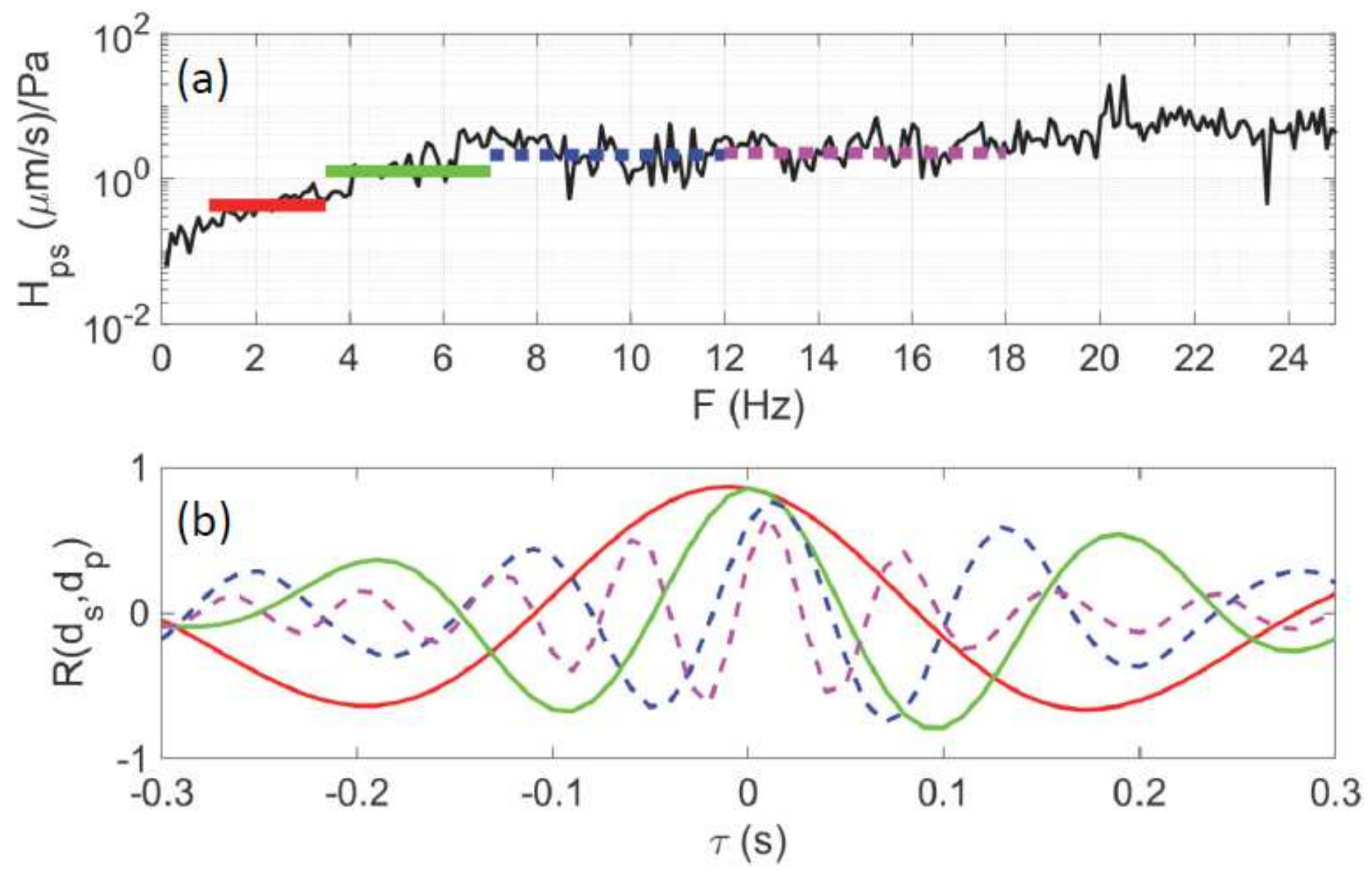

Figure 3

(a) The amplitude response of the ground velocity to infrasound, $\mathrm{Hps}$, obtained by this study is shown 314 for $1-3.5 \mathrm{~Hz}$ (red line), 3.5-7 Hz (green line), 7-12 Hz (blue dots), and 12-18 Hz (purple dots). The 315 results are compared with the response function obtained by Ichihara [2016] (Fig. 1d and 1e). (b) The corresponding cross-correlation coefficient between the phase-shifted seismic data, dhv 316 , and the infrasonic 317 data, dp. The colors indicate the frequency bands as in (a). 

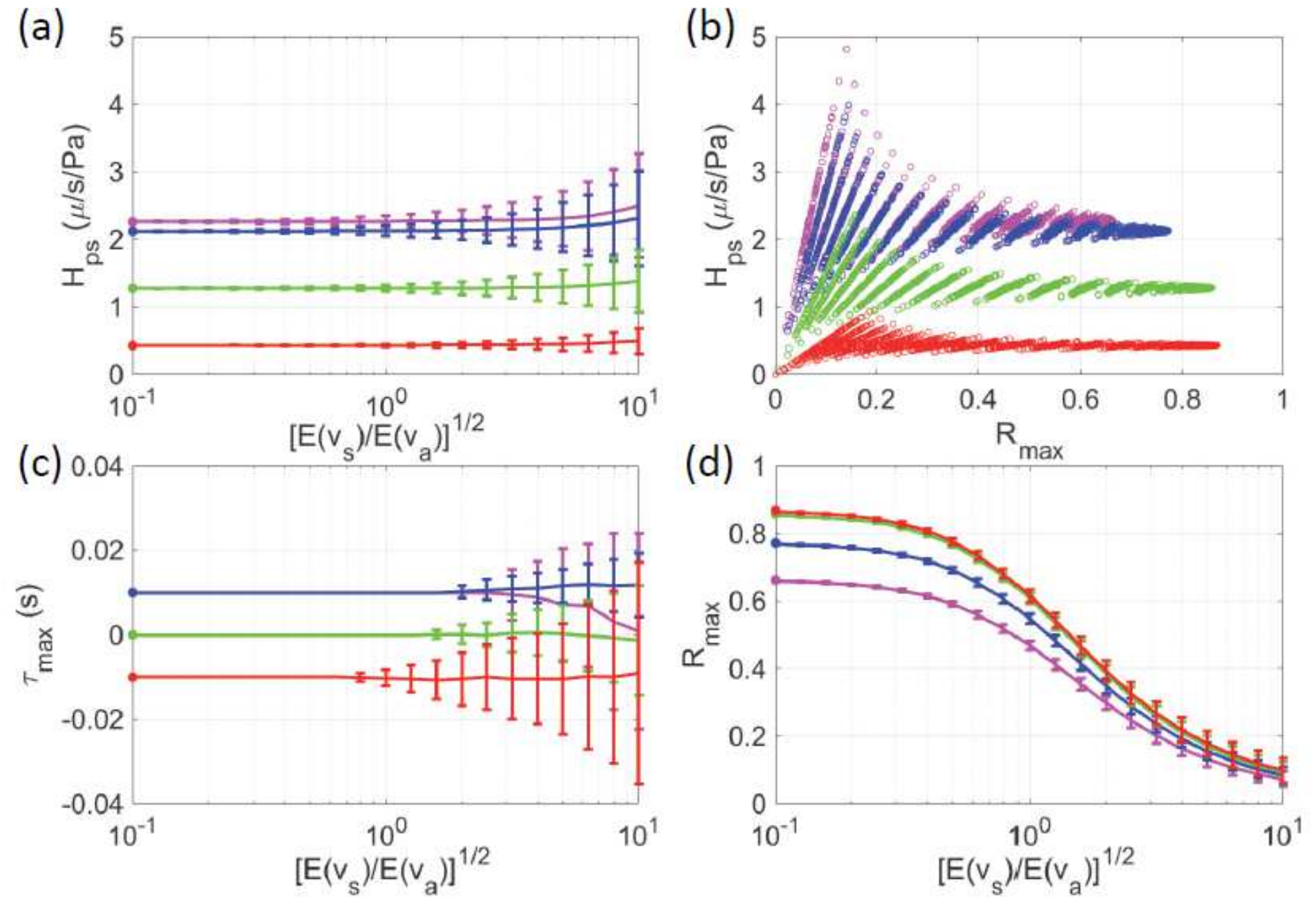

\section{Figure 4}

The effect of background seismic signals, vs, in the seismic data, dv, on the estimation of Hps. The colors indicate the frequency bands: $1-3.5 \mathrm{~Hz}$ (red), $3.5-7 \mathrm{~Hz}$ (green), 7-12 Hz (blue), and 12-18 Hz (purple). A hundred random functions are band-pass filtered and used as vs. The horizontal axis is the square-root of power ratio of vs to the original $d v$ that is approximated as va. It is noted that the actual power ratio $\mathrm{E}(\mathrm{vs}) / \mathrm{E}(\mathrm{va})$ is larger than $\mathrm{E}(\mathrm{vs}) / \mathrm{E}(\mathrm{dv})$ as dv itself contains a significant power of background signals. The lines and error bars show the means and the standard deviations of Hps (a), the maximum correlation coefficient, Rmax (d), and the time delay, tmax, that gives Rmax (d) for the hundred random functions. The closed circles on the vertical axies are the values without vs. The relation between 327 the individual Rmax and Hps for all the cases are shown with circles in (b). 
(a)

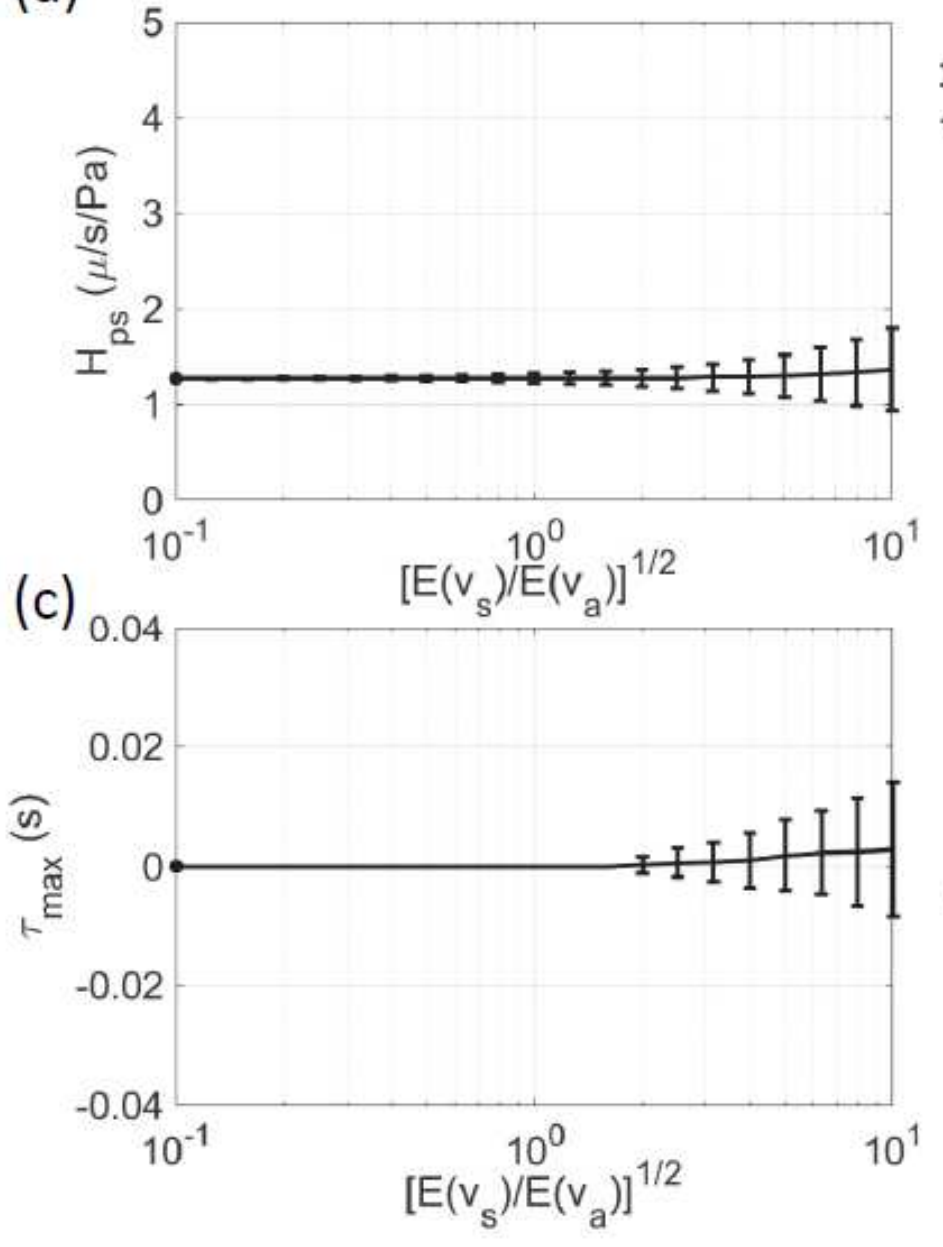

(b)
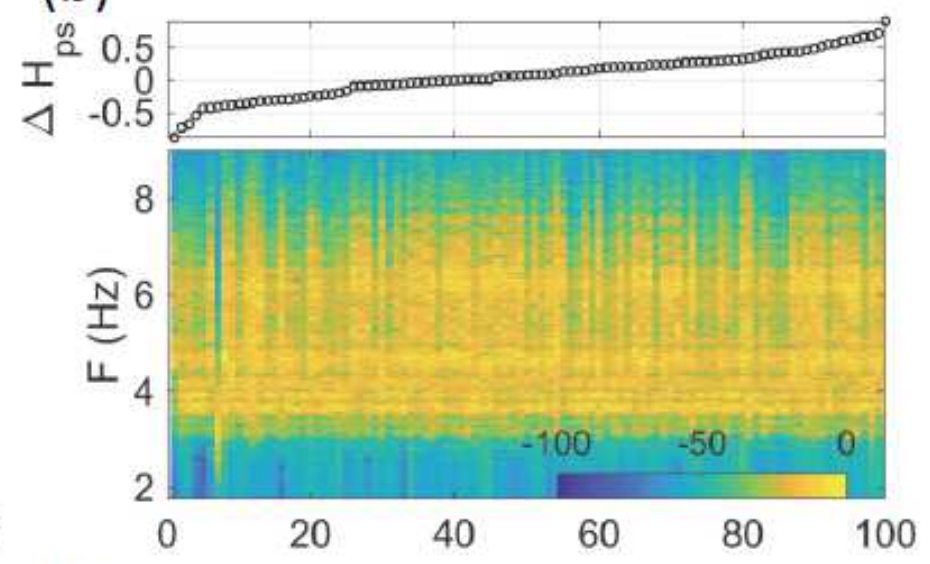

(d)

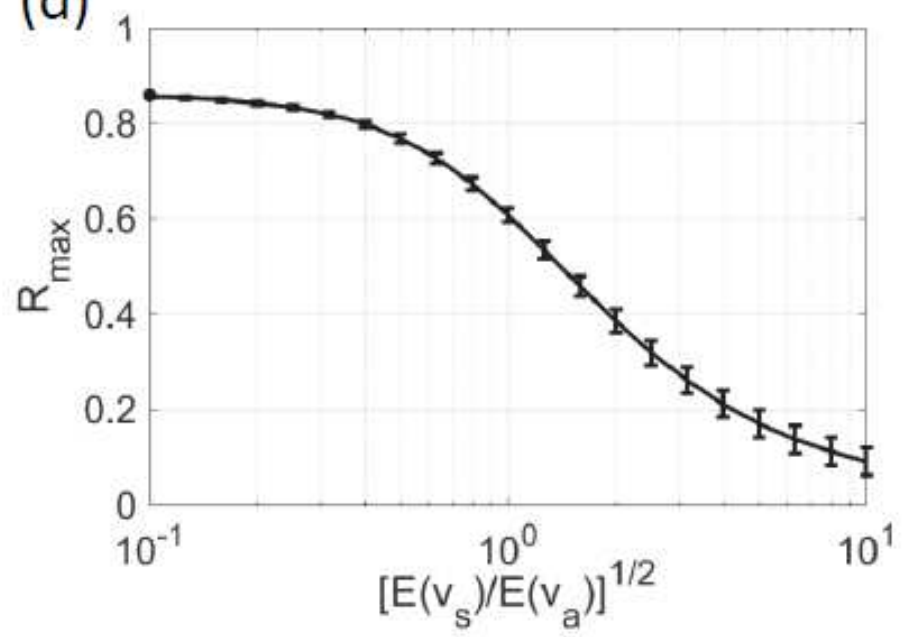

\section{Figure 5}

A similar background-signal test as in Fig. 4, but volcanic tremors recorded by the same seismic station are used as vs. We performed the analysis only at $3.5-7 \mathrm{~Hz}$. We randomly selected 100 -time windows between 1:27 on 19 January 2011 and 7:31 on 26 January 2011, of which the normalized power-spectral densities of the band-pass-filtered data are displayed in the lower panel of (b). The horizontal axis shows the window number of vs aligned in the increasing order the deviation of Hps for the case $\sqrt{E}(v s) / E(v a)=$ 10. The upper frame shows the deviation: $\Delta \mathrm{Hps} \otimes(\mathrm{Hps}-\mathrm{HOps}) / \mathrm{HOps}$, where $\mathrm{HO} \mathrm{ps}$ is the value obtained without vs, which is the closed circle on the vertical axis in (a). In (a), (c), and (d), the lines and error bars show the means and the standard deviations of Hps, tmax, and Rmax, respectively.

\section{Supplementary Files}

This is a list of supplementary files associated with this preprint. Click to download.

- GraphicalAbst.pdf

- IchiharaEPS2021AdditionalFile.pdf 